\title{
Information on the Thematic Issue Dedicated to R.A. Buyanov
}

DOI: $10.1134 / \mathrm{S} 0023158421440014$

\section{DEAR COLLEAGUES!}

The editors of the "Kinetics and Catalysis" journal plan to publish a thematic issue, which will be published in No. 1, 2022, and will be dedicated to the memory of one of the founders of the Boreskov Institute of Catalysis SB RAS, a corresponding member of RAS Buyanov Roman Alekseevich (21.02.192704.12.2020).

The research activity of R.A. Buyanov is associated with the development of the scientific foundations for the preparation of catalysts and carbon-mineral supports, including the use of mechanochemistry. Studying the causes of deactivation and destruction of industrial catalysts, he gave them a scientific classification and revealed the mechanism of the "carbide cycle" in the carburization of catalysts. With the direct participation of Roman Alekseevich, catalysts for the production of synthetic rubber monomers, Claus sulfur purification catalysts, carbon-mineral supports, and vinyl chloride production catalysts, aluminum oxide-based supports, dehydrogenation catalysts, etc. have been developed and implemented in industry. Buyanov R.A. developed a fundamental theory of the magnetic action of catalysts in the low-temperature conversion of ortho-hydrogen to para-hydrogen. These works culminated in the creation of the industrial production of liquid para-hydrogen - rocket fuel, on which the Buran spacecraft flew.

We invite you and your colleagues to participate in the thematic issue and send the manuscript of your article by August 31, 2021 (in some cases, the submission dates can be discussed with the editors). We remind that the subject of the journal covers the mechanisms and kinetics of catalytic processes in the gas, liquid, and solid phases, the preparation of catalysts, the problems of their deactivation, macrokinetics, and computer modeling in the field of catalysis. 